\title{
RECONSIDERANDO A ETNOGRAFIA DA CIÊNCIA E DA TECNOLOGIA \\ Tecnociência na prática
}

\section{Marko Synésio Alves Monteiro}

\section{Introdução: adentrando o laboratório}

Tradicionalmente usada como método na antropologia, a etnografia muitas vezes é discutida como uma espécie de elemento definidor dessa disciplina (Laplantine, 1999; Vidich e Lyman, 2000). Como método de análise, no entanto, ela vem sendo cada vez mais debatida, analisada e apropriada pelos mais diversos campos do conhecimento (Bogdan e Biklen, 1994; Vidich e Lyman, 2000), dentro e fora das ciências sociais. Mais especificamente para os Estudos Sociais de Ciência e Tecnologia (ESCT), o uso da etnografia significou uma virada importante nesse campo, marcando o rompimento de um grupo de autores com as abordagens estruturalistas ligadas a Robert Merton (1973) e sua sociologia da ciência. Esse grupo encampou um programa de estudos da ciência que levasse em

Artigo recebido em 10/02/2011

Aprovado em 01/12/2011 conta a produção do conhecimento no seu núcleo mais "duro", o interior do laboratório (Knorr-Cetina, 1981; Latour e Woolgar, 1997; Sismondo, 2004). Essa virada marcou também o crescimento dos ESCT nas últimas décadas como um campo disciplinar institucionalizado, reorganizando seu foco em torno de estudos de caso e sugerindo o paradigma socioconstrucionista como sua principal fronteira de expansão. ${ }^{1}$

De forma associada, e paralelamente, a antropologia começou, nesse mesmo período, a produzir um grande número de estudos sobre temas ligados à ciência e à tecnologia (Hess, 2001; Martin, 1998). Tal movimento é relativamente recente, dada a associação clássica entre antropologia e culturas não ocidentais, contextos "tradicionais" e saberes não científicos. A ideia de que caberia ao antropólogo conhecer contextos não industrializados, de baixo desenvolvimento tecnológico e com uma cultura material "pobre" (sempre pensa- 
dos em contraste a um Ocidente industrializado) solidificou uma divisão intelectual do trabalho que excluiu por muito tempo os questionamentos mais propriamente antropológicos de contextos considerados de alta tecnologia ou nos quais ocorre a produção de conhecimento científico.

Tal divisão não é fortuita: tida como bastião da racionalidade ocidental, a ciência contemporânea configura a esfera de produção de verdades e saberes mais valorizada pelas sociedades industrializadas. O conhecimento científico, como atestam os ESCT, possui no Ocidente um caráter quase sagrado, uma vez que evita a todo custo questionamentos sobre as condições de sua produção. Da mesma maneira, os agentes envolvidos nesses processos possuem enorme prestígio social, o que também insere seu estudo no dilema tratado pela antropologia como studying up: acostumada a estudar sociedades colonizadas por europeus, países de industrialização emergente, culturas isoladas ou regiōes marginais de grandes cidades, a antropologia eximia-se de analisar os extratos mais ricos e poderosos das sociedades ocidentais, avessos por conta de sua posição a questionamentos de suas práticas (Marcus e Fischer, 1999; Nader, 1972).

$\mathrm{O}$ atual crescimento do interesse pela etnografia por parte de diversos campos disciplinares, no entanto, não veio necessariamente acompanhado de uma reflexão mais aprofundada a respeito do alcance e dos limites implicados no uso desse método. Mais especificamente no contexto dos ESCT, ainda que estudos detalhados de práticas laboratoriais se tornem cada vez mais populares, poucos trabalhos tratam diretamente do método etnográfico como metodologia de análise. Com exceção de algumas poucas revisões bibliográficas, como as de David Hess (2001), Emily Martin (1998) e Bryan Pfaffenberger (1992), o debate sobre etnografia nos ESCT permanece marcado por seus discursos inaugurais, proferidos por Bruno Latour e Woolgar (1997) e Karin Knorr-Cetina (1983a).

Essa ausência de questionamento leva à proliferação de discursos sobre a etnografia como um método restrito ao âmbito do "micro", como se a observação participante restringisse o pesquisador às práticas cotidianas dos cientistas e não possibilitasse questionamentos sociológicos mais globais acerca da ciência e da tecnologia. Alguns críticos chegam a se referir a essa abordagem como uma "crônica" do fazer científico (Freitas, 2005), rechaçando qualquer contribuição positiva dessa abordagem para o conhecimento sobre a tecnociência. ${ }^{2}$ Essa imagem por vezes negativa da etnografia como mero registro empiricista de práticas deixa de lado suas contribuições mais importantes, incluindo a forma como permite captar o caráter processual e construído do conhecimento, sua contextualidade, seu caráter indexical e sua materialidade negociada entre uma diversidade de atores, humanos e não humanos.

Longe de ser um método que restrinja o alcance da análise, a etnografia sugere formas de reflexão que ampliam o alcance dos ESCT, como será argumentado a seguir. $\mathrm{O}$ presente trabalho busca, assim, revisitar a discussão do método etnográfico no contexto dos ESCT, ressaltando suas vantagens e tornando mais claras as formas pelas quais as especificidades desse método permitem análises da tecnociência que não são desenvolvidas por outras abordagens. Entre essas, a ideia da tecnociência como uma prática, desenvolvida em contextos particulares e possuindo caráter processual; e a noção de "fato social total" (Mauss, 2005) como uma opção teórica para a superação das divisões ontológicas entre ciência, tecnologia e sociedade.

Limitar o debate etnográfico sobre a ciência (dentro e fora dos ESCT) a uma pura descrição do que os cientistas fazem no interior de laboratórios é perder de vista o alcance dos questionamentos sobre o conhecimento científico realizados pelos chamados "estudos de laboratório", que são uma das vertentes mais conhecidas e debatidas dos estudos sobre ciência e tecnologia. Ao mesmo tempo, ignorar a contribuição que essa abordagem tem tido não só no campo dos ESCT, mas também na reflexão sobre políticas científicas é perder de vista o enorme alcance que métodos etnográficos podem ter na nossa realidade atual, marcada pela constante inovação tecnológica e pela crença na ciência como forma privilegiada de tradução da verdade sobre o mundo natural.

O objetivo deste trabalho é, portanto, contribuir para o diálogo a respeito da etnografia como forma de conhecer nossa realidade "tecnocientífica”, buscando pensar alternativas metodológicas 
para o estudo de questões de ciência e tecnologia que sejam não apenas úteis ao pesquisador, mas que abram também alternativas para profissionais e formuladores de política interessados em repensar tanto práticas de conhecimento como a formulação e a aplicação de novas tecnologias.

\section{Etnografia e tecnociência}

O que seria então fazer "etnografia da ciência"? Seria a observação direta dos processos de constituição dos saberes científicos (science in the making)? Seria a descrição dos procedimentos pelos quais cientistas descobrem verdades sobre a natureza? Seria a denúncia do caráter construído desse conhecimento, dado o número de fatores "extracientíficos" associados ao fazer científico?

Fazer etnografia de práticas científicas muitas vezes se confunde com a perspectiva socioconstrucionista, a ela fortemente associada, servindo de base para estudos que mostram o caráter construído e "impuro" das atividades que ocorrem dentro de laboratórios. O laboratório emerge, dessa forma, como um dos focos centrais dos ESCT contemporâneos (Knorr-Cetina, 1992), num movimento que redefine os estudos da ciência e a sociologia da ciência ao redor da ideia de construção social (Knorr-Cetina, 1983a). No entanto, não há consenso em torno do que significa fazer "etnografia da ciência", mas a convivência de várias abordagens que vêm trazendo à tona a riqueza e a diversidade de práticas e relações que compõem os contextos tecnocientíficos.

\section{A apropriação da etnografia pelos ESCT}

Os ESCT compõem uma área multidisciplinar que vem crescendo ao redor do mundo de forma consistente desde pelo menos os anos de 1970 , com a multiplicação de projetos de pesquisa, a criação de programas de pós-graduação nas principais universidades e a incorporação, especialmente em países como Estados Unidos, Inglaterra, França, Alemanha e países escandinavos, da perspectiva "social" em grandes projetos de pesquisa interdisciplinares. Inicialmente associada a estudos da história, filosofia e sociologia do conhecimen- to científico, essa área vem incorporando métodos e teorias antropológicas, ampliando o escopo das suas pesquisas e renovando pesquisas dentro e fora dos ESCT (Pestre, 1996).

O impacto das pesquisas a respeito da natureza do conhecimento científico, representadas pela obra de autores como Thomas Kuhn (1970) e, posteriormente, pelos debates acerca do Programa Forte (Strong Programme) (Bloor, 1976), ajudou a ampliar em muito o interesse pelo estudo social das ciências, abrindo caminho para um tratamento propriamente sociológico do próprio conhecimento científico. Se antes a sociologia da ciência era a sociologia do erro, ou seja, daqueles elementos que causariam distorções na produção do conhecimento (este sempre intocável para a sociologia), com o Programa Forte e outras abordagens, é a própria ciência e sua objetividade que se tornam objetos da análise social. Essa perspectiva prometia um estudo social da ciência muito mais profundo e revolucionário do que tudo que havia sido feito até então (Knorr-Cetina, 1983b; Sismondo, 2004; Woolgar, 1982).

Parte importante desse movimento foi a incorporação da etnografia no estudo das práticas científicas a partir de fins dos anos de 1970. Segundo Karin Knorr-Cetina (1983a), ela mesma pioneira nessa apropriação, a abordagem etnográfica de práticas científicas colaborou para abrir a "caixa preta" do método científico. Ela cita, dentre as inovações trazidas por estudos etnográficos da ciência, a abordagem construtivista do conhecimento científico e uma reiteração do caráter contextual da prática científica. Enquanto a primeira tem sido relevante nos debates acerca da ciência experimental como prática de construção de verdades e de conhecimento, a segunda traz para o estudo social das ciências aquilo que a circunda: o tempo-espaço no qual se insere.

A passagem de uma análise minuciosa da produção do conhecimento tal qual ocorre na sua prática, consagrada por autores como Bruno Latour, Michael Lynch, Steve Woolgar e Karin Knorr-Cetina para o contexto social na qual se insere, fazendo assim a ponte entre o interior do laboratório e seu entorno, tem sido uma orientação cada vez mais relevante nos ESTC, justamente na sua interseção com a etnografia. 
A abordagem construtivista do conhecimento popularizou-se no Brasil principalmente associada a autores como Bruno Latour e Steve Woolgar (1997), cujo estudo pioneiro postula o caráter construído do conhecimento científico e recusa a ideia de que o saber produzido em laboratório incorpora uma verdade metafísica sobre o objeto; ou que seja uma construção subjetiva do cientista, uma mera imagem mental. O saber científico, segundo essa perspectiva, não depende de nenhuma relação necessária com a "natureza" externa a ele, nem de uma relação interna com aspectos do pensamento ou da cognição, mas constrói e reproduz objetos e traços escritos e visuais que representam aquilo que consideramos "conhecimento" (Latour, 1990).

É importante ressaltar, no entanto, que Bruno Latour vem fazendo uma importante crítica da ideia de construção social, em paralelo a outros autores inicialmente associados a essa ideia, como Michael Lynch. Para Latour (2005), que busca abolir a própria ideia durkheimiana de "social", não há divisão a priori entre natural/social, humano/não humano, ciência/sociedade; seria a própria tarefa da sociologia, por ele repensada como "sociologia das associações" (em oposição à "sociologia do social" ligada a Durkheim), reconstruir a maneira pela qual tais oposiçôes constituem-se como realidades. Sua noção de construção, dessa forma, é bastante distinta de qualquer socioconstrucionismo, e tem influência da etnometodologia, trabalhada de forma mais aprofundada no campo dos ESCT por Michael Lynch (Garfinkel, 1967; Lynch, 1993).

Lynch também critica a ideia de um socioconstrucionismo, mas sem filiar-se à Teoria Ator-Rede ou à sociologia das associações propostas por Latour e outros. Para ele, a crítica à sociologia está mais relacionada com os fundamentos da própria etnometodologia, que foca suas análises na processualidade do social e vê a ordem social não como imposta por estruturas ou forças externas, mas como algo inerente à própria socialidade e reconstituída constantemente na prática (Lynch, 1993).

Contudo, há importantes pontos de encontro entre essas diversas vertentes que merecem breve comentário, auxiliando a perceber a especificidade da contribuição etnográfica. Segundo Knorr-Cetina (1983a), especialmente ao permitir a análise minu- ciosa do processo do fazer científico, estudos etnográficos da ciência vêm demonstrando o seu caráter localizado, indeterminado e contextual. Os estudos mais etnometodológicos, vistos como vertente à parte, analisam as formas pelas quais a inteligibilidade dos objetos científicos emergem no decorrer de práticas e interações que ocorrem no cotidiano do laboratório (Lynch, 1982), inspirando também diversos estudos mais propriamente linguísticos e cognitivos sobre as inter-relações entre cientistas e os objetos que produzem e manipulam no decorrer de suas atividades (Goodwin, 1994; Keating, 2005; Monteiro, 2010a e b; Monteiro e Keating, 2009; Ochs et al., 1994). Dessa forma, a processualidade, a indeterminação e a atenção ao caráter contextual da ciência são pontos focais nas escolas inspiradas pela etnografia.

Tais elementos são debatidos também pela Teoria Ator-Rede, ainda que esta geralmente se considere uma vertente à parte e não necessariamente uma metodologia etnográfica stritu sensu (Latour, 2005; Law, 2009). Outras abordagens também assumem posturas metodológicas semelhantes, e vale mencionar especialmente Andrew Pickering (1993) e sua discussão sobre práticas. Pickering, ainda que por ela inspirado, mantém-se distinto da abordagem ator-rede, e não se filia também explicitamente enquanto etnógrafo. Ainda assim, seu foco metodológico na praxiologia da ciência possui pontos de forte interesse para qualquer pesquisador interessado em etnografias da ciência e da tecnologia.

David Hess (2001) argumenta que os primeiros estudos sobre produção de conhecimento configuram uma primeira onda de etnografias, na qual o foco era o laboratório, tanto como lócus privilegiado de pesquisa quanto como conceito a partir do qual se compreende a noção de construção social. Há, ainda segundo Hess, uma segunda onda de etnografias, mais preocupadas com o contexto ao redor do laboratório e com as relaçôes entre laboratório e "sociedade", de pontos de vista diversos. Autores como Hess, a partir de campos disciplinares variados que incluem o feminismo, a antropologia, a linguística, os estudos culturais e os próprios ESCT, buscam ampliar o escopo das análises etnográficas da tecnociência, tirando o foco exclusivo sobre a prática laboratorial stritu sensu e buscando um foco nas interações que compõem a ciência como prática social. 


\section{Antropologia e tecnociência}

Os estudos propriamente antropológicos sobre ciência e tecnologia não se desenvolvem necessariamente em proximidade com os desenvolvimentos descritos anteriormente nos ESCT. Ainda assim, há um claro crescimento do interesse de antropólogos sobre esse tema ao redor do mundo, incluindo o Brasil (Sautchuk, 2010), como atestam trabalhos recentes sobre células-tronco (Luna, 2007), primatólogos (Sá, 2005), tecnologias de visualização do interior do corpo (Chazan, 2008), entre muitos outros. Alguns autores, como Emily Martin, indicam a noção de cultura como sendo o diferencial antropológico em relação ao estudo da ciência e da tecnologia (Martin, 1998), enquanto outros apontam o foco metodológico e conceitual próprio, que inclui desde a etnografia até conceitos específicos como o de fato social total e a tradição de estudos sobre cultura material (Pfaffenberger, 1988, 1992); outros ainda dirigem o olhar para a interação entre laboratório e sociedade como uma contribuição específica da antropologia da ciência e da tecnologia (Franklin, 1995).

Sem a pretensão de sistematizar uma abordagem antropológica generalizante sobre ciência e tecnologia, dado que qualquer metodologia é necessariamente plural e multifacetada, discutimos a seguir alguns dos antecedentes teórico-metodológicos que informam uma linhagem mais especificamente antropológica de estudos etnográficos sobre práticas e contextos tecnocientíficos. Dentre eles, apontamos mais enfaticamente os estudos feministas e de gênero, que foram pioneiros em abordar a tecnologia e sua relação com corpos, processos biológicos e relações de poder; e uma leva crescente de autores interessados em práticas ligadas à genômica e outras biotecnologias emergentes, num movimento também relacionado com debates metodológicos na disciplina, ligados à crítica pós-moderna (Franklin, 1995).

Essas linhagens, atualmente, estão cada vez menos separadas daquilo que se considera os ESCT, um movimento salutar de diálogo interdisciplinar de metodologias e vertentes teóricas. A discussão que segue não busca, assim, delinear as fronteiras de campos disciplinares; pelo contrário, pretende fornecer subsídios para um debate acerca das possibilidades da etnografia em enriquecer a nossa compreensão atual sobre ciência e tecnologia.

\section{Feminismo e tecnologia}

Os estudos feministas e de gênero recentes passaram a prestar cada vez mais atenção na questão da ciência e da tecnologia, especialmente a partir dos trabalhos de Donna Haraway (1989, 2004) e Evelyn Fox Keller (1995). Ambas, de pontos de vista distintos, trouxeram à tona a importância de se compreender dinâmicas tecnológicas para os estudos feministas e de gênero, e para a compreensão da situação de desigualdade entre homens e mulheres. A questão é hoje amplamente consolidada nas discussóes feministas, e esse ímpeto renovador teve seus efeitos sentidos também no mainstream antropológico.

Haraway, além de influente historiadora da ciência, começa a deixar sua marca e forma mais relevante a partir do conceito de ciborgue (Haraway, $1995,2000)$, proposto como figura mítica de inspiração para a luta das mulheres e também como saída analítica para dilemas aparentemente insolúveis com ferramentas teóricas tradicionais. O ciborgue de Haraway incorpora elementos biológicos e tecnológicos, suplantando a divisão ontológica entre natureza e cultura. O manifesto político-metodológico de Haraway visa, assim, chamar o feminismo a recriar categorias e corpos de forma a superar desigualdades num mundo que se torna cada vez mais perpassado pela tecnociência (Haraway, 1997).

$\mathrm{O}$ impacto de Haraway vai muito além do Manifesto Ciborgue, talvez seu trabalho mais conhecido. A autora contribuiu para pensar uma epistemologia propriamente feminista, com a noção de perspectivas parciais (standpoint theory) (Haraway, 2004); escreveu também textos antológicos sobre a relação entre tecnologias reprodutivas e corpos femininos, tema de relevância crescente. Seus textos sobre primatologia (Haraway, 1989), ainda que menos lidos no Brasil, permanecem exemplos clássicos de estudos críticos sobre ciência e sobre a negociação de fronteiras entre o natural e o humano (ou o social) que dialogam diretamente com ondas recentes no interior dos ESCT, como a Teoria Ator-Rede. 
Um dos focos mais importantes da discussão acadêmica sobre gênero envolve um duplo questionamento sobre o conhecimento: primeiro, uma crítica sobre a ciência neutra, a partir de uma reflexão sobre a parcialidade do conhecimento; segundo, análises de como o conhecimento científico sobre as mulheres e a reprodução participa de processos de naturalização da desigualdade. Nessa dupla desconstrução, as teorias feministas têm sido fonte de inspiração para os ESCT, e hoje são tidas como parte importante daquilo que se considera o campo de estudos de ciência, assim como da própria antropologia.

Partindo da premissa de que a análise feminista deve rechaçar uma ciência supostamente neutra (Bordo, 1986) e assumir a sua posicionalidade como parte intrínseca da sua prática política e intelectual (Haraway, 2004), as feministas vêm colocando em questão, como tantos outros autores inspirados por movimentos intelectuais pós-modernos, o sujeito do conhecimento e a parcialidade dos saberes por ele(a) construídos. $\mathrm{Na}$ antropologia, debates sobre reflexividade e sobre a escrita etnográfica marcaram profundamente discussões recentes da disciplina (Clifford e Marcus, 1986), num movimento crítico ao suposto distanciamento do sujeito que conhece diante de seu objeto.

Ao mesmo tempo, a análise feminista tratou também de desconstruir a ciência produzida sobre o corpo e sobre a reprodução, a fim de compreender melhor a naturalização das desigualdades entre homens e mulheres a partir da biologia (Bordo, 1989; Butler, 1990; Haraway, 1992; Keller, 1995). A questão da análise do conhecimento científico sobre o corpo humano e a reprodução como forma de compreensão da naturalização de hierarquias é um dos focos centrais da análise de gênero, sendo ainda um dos campos mais férteis da crítica feminista. Keller (1995), por exemplo, ao analisar as metáforas constitutivas da nossa compreensão sobre a biologia, ajuda a pensar como o conhecimento científico funciona para naturalizar corpos e relaçôes sociais, assim como amplia o escopo da crítica sobre a ciência a partir da análise crítica da genética.

A análise crítica do conhecimento científico tem sido, dessa forma, central para as teorias feminis- tas recentes, de forma mais ou menos paralela aos ESCT. Atualmente, ocorre um intenso diálogo entre esses campos, sendo que abordagens etnográficas estão entre as mais utilizadas por pesquisas preocupadas em investigar gênero, ciência e tecnologia.

\section{A critica epistemológica: natureza versus cultura}

Outro foco significativo de análises etnográficas sobre ciência e tecnologia são os estudos com foco na biotecnologia, ainda que relacionados a diversos temas: saúde/doença, natureza/cultura, ontologias do corpo e identidades contemporâneas. As pesquisas com biotecnologias foram importantes num momento histórico, em fins do século XX, de retorno de metáforas essencialistas na cultura, que recuperavam o gene como "essência" do social, da identidade e da doença (Keller, 1995). Estavam em discussão não somente a biotecnologia como prática tecnocientífica, mas também conceitos caros à análise social, como identidade, representação e a dualidade natureza/cultura, todos, segundo alguns autores, fadados à obsolescência em face de novos desenvolvimentos tecnológicos que prometiam acesso irrestrito ao "livro da vida" (Kay, 2000).

Entre os antropólogos, Paul Rabinow (1999a e b, 2000) permanece até hoje uma referência fundamental para o debate sobre as novas biotecnologias. Sua noção de "biossocialidade" (ou "biossociabilidade") visa oferecer uma interpretação de como a incorporação de conhecimento sobre a genética e tecnologias de sequenciamento afeta dinâmicas sociais, tornando a composição biológica parte fundamental de processos de identificação e de movimentação política. Rabinow questiona, ainda, as divisões ontológicas entre natural/cultural arraigadas no pensamento antropológico tradicional. Tais dualidades sofrem contínuo ataque a partir do final do século XX, dentro e fora da chamada crítica pós-moderna na antropologia (Clifford e Marcus, 1986), instigando diversos autores a analisar alternativas a essa dualidade.

No contexto dessa crítica metodológica, vale mencionar a proposta para uma "antropologia ciborgue" (Downey et al., 1995), que teve bastante impacto na virada para os anos 2000. Os formuladores dessa discussão buscavam abordar teorica- 
mente tanto o esgotamento de divisões ontológicas, tais quais a de natureza/cultura, como a necessidade de a antropologia oferecer interpretações para as novas socialidades, nas quais a tecnologia e sua relação com processos sociais eram de fundamental importância. Além disso, eles buscavam afirmar as relações complexas entre tecnologias e corpos. A antropologia ciborgue levantou temas que dialogam diretamente com outras propostas metodológicas atuais, como a etnografia multissituada (multi-sited ethnography) (Marcus, 1995), que chama a atenção para processos sociais contemporâneos no contexto do chamado sistema mundial, o capitalismo globalizado e a centralidade das novas tecnologias.

Esses desenvolvimentos no âmbito da antropologia recente trazem formas inovadoras de abordar analiticamente processos que envolvem ciência e tecnologia. A etnografia multissituada chama a atenção para a necessidade de perceber fenômenos que perpassam fronteiras espaciais bem delimitadas, como a aldeia ou o laboratório. Nossa compreensão das formas pelas quais tecnologias participam da construção da sociedade contemporânea fica necessariamente limitada ao ignorarmos, por exemplo, a circulação de bens, conhecimentos e pessoas em circuitos globais. Nesses circuitos, artefatos e saberes produzidos em laboratórios transitam em rotas complexas que interagem com instituições científicas, governos, mídia e organizações sociais as mais diversificadas.

Ciência e tecnologia estão, dessa forma, profundamente ligadas a circuitos econômicos globais, tanto em termos do financiamento de pesquisas, como em termos de sua posterior circulação. Sistemas de patentes, de comunicação científica e de apropriação tecnológica são perpassados por variáveis diversas cada vez mais globais. Entender um artefato, como uma nova aplicação nanotecnológica para uso humano, ou um novo teste genético para o câncer, envolve compreender as complexas relações das quais esta tecnologia não é mais do que um nódulo. Delimitar a priori objetos discretos (um cientista, um chip de DNA ou uma nanopartícula) como foco exclusivo da análise é limitar indevidamente a compreensão de como esse artefato emerge de e participa em circuitos complexos e dinâmicos de relações.
Em outras palavras, a discussão sobre biotecnologias e sobre a dualidade ontológica natureza/ cultura, que marca muitos estudos etnográficos sobre ciência e tecnologia, abrem caminhos frutíferos para o repensar das formas pelas quais delimitamos nossos objetos de pesquisa e formulamos nossas críticas. Em que medida estamos separados dos objetos que estudamos? De que forma os conhecimentos que analisamos participam de dinâmicas sociais e relaçōes de poder? Como artefatos específicos constrangem tanto nossas formas de conhecimento quanto nossa própria materialidade? Como repensar o foco em objetos discretos (pessoas, artefatos, símbolos) e realinhar nosso olhar analítico para processos e relaçôes? Essas questôes, relacionadas com inovações da tecnociência contemporânea, demandam uma abordagem também inovadora e aberta para a complexidade.

\section{Ciência, tecnologia e sociedade na prática}

Uma abordagem etnográfica oferece saídas analíticas para repensar temas relacionados com a ciência e a tecnologia que ainda não foram explorados exaustivamente no contexto dos ESCT ou de outras disciplinas. Abordam-se aqui duas em específico: a discussão sobre fato social total e a teoria das práticas. A primeira possibilita a análise, de forma integrada, de variáveis e elementos geralmente pensados de forma separada, como o social, o econômico, o tecnológico, o simbólico etc. A segunda permite um quadro interpretativo que apreende os fenômenos como processos em fluxo, focando relações e não elementos em separado. Sugerimos aqui dois elementos: a) um pensamento que não despe fenômenos sociais de sua complexidade, composta de uma diversidade de variáveis que atuam em conjunto; e b) uma abordagem focada não em "sujeitos", "objetos" e "artefatos" ontologicamente distintos, mas em processos e relações centrais na abordagem de contextos e de fenômenos relacionados com tecnociência.

Emily Martin (1998) sugere temas semelhantes na sua revisão da bibliografia antropológica sobre ciência e tecnologia, utilizando as imagens do rizoma e da cidadela como mote da discussão. Ela 
contrapõe a noção tradicional da ciência como cidadela isolada com a ideia da inter-relação rizomática entre instituições científicas e o contexto social, enfatizando a importância de se levar em conta a construção integrada entre laboratório e sociedade. Além disso, a ideia de rizoma permite, segundo a autora, a interpelação das porosidades entre áreas consideradas separadas.

Entretanto, a ideia de incluir o "contexto social" no estudo de tecnologias pode, inadvertidamente, reforçar uma separação ontológica que reitera a existência separada das esferas do social e do tecnocientífico. Tal separação, criticada por vários autores, pressupõe a existência da sociedade como elemento discreto, à parte dos elementos que a compóem. O debate acerca do determinismo social ou tecnológico, recorrente em discussões sociocientíficas sobre tecnociência, é, a nosso ver, improdutivo. Ele mascara ou torna inviável discussões mais fecundas sobre como artefatos, humanos e símbolos interagem em situações concretas.

A ideia da tecnologia como fato social total, sugerida por Bryan Pfaffenberger $(1988,1992)$, é uma tentativa de escapar desse dilema simplificador. Essa noção é derivada das análises de Marcel Mauss (2005), que discute as inter-relações entre diferentes esferas da sociedade, tradicionalmente pensadas de forma separada.

Pfaffenberger, ao comentar as possibilidades de uma antropologia da técnica, compara duas formas tipicamente "ocidentais" de lidar analiticamente com o tema, cuja análise explicita o papel particular que ela tem no pensamento ocidental. A primeira seria uma espécie de "sonambulismo tecnológico", que não vê nada de particularmente digno de nota na tecnologia. Essa atitude supōe que ferramentas são apenas meios para cumprir alguma tarefa, ou seja, que elas não possuem nenhum significado intrinsecamente social, são objetos inertes. O oposto dessa visão é o "determinismo tecnológico", que atribui à tecnologia poder de definição da vida social. Como se os eventos da história fossem ditados pelo progresso inexorável da tecnologia, que seriam assim formadores da sociedade e não o contrário. Pfaffenberger recusa as duas teses, mostrando que toda tecnologia e seus usos são fruto de escolhas e interações. Falar em termos de "impacto" de uma tecnologia sobre a sociedade, ou vice-versa, seria perder de vista o caráter intrinsecamente social de qualquer tecnologia.

Para o autor, a tecnologia é a "natureza humanizada”, ou seja, é a construção da natureza pela sociedade, incorporando relações e significados: uma forma de vida. Nesse sentido, é um fato social total: simultaneamente social, política e simbólica, a tecnologia agrega diversos âmbitos da sociedade, sendo portanto impossível compreendê-la sem levar em conta esse seu aspecto multifacetado. Pfaffenberger cita um exemplo empírico para ilustrar seu argumento: os sistemas de irrigação em Sri Lanka. Para entender por que a criação de sistemas de irrigação não sanou desigualdades sociais, é necessário compreender de forma integrada aspectos técnicos (agricultores próximos das barragens conseguiam obter mais água e tinham melhor produtividade), socioculturais (as desigualdades de renda assim causadas reforçaram as desigualdades sociais típicas do contexto local) e político-econômicos (houve um aumento da produção de arroz com importantes consequências econômicas, o que não amenizou o fracasso das barragens em reduzir desigualdades, impedindo que agricultores sem terra fossem positivamente impactados pelas políticas públicas em questão).

Pfaffenberger (1992) critica o que ele chama de visão padrão da tecnologia. Refuta a ideia de que objetos técnicos surgem para cumprir funções práticas específicas; ou, em outros termos, de que a tecnologia de determinada cultura advém da busca para suprir suas necessidades materiais básicas (água, comida, transporte), estando, assim, fracamente vinculada aos significados criados nesse contexto. Tal visão engessa a tecnologia em objetos, dissociando-os da cultura. Assume-se que necessidades básicas são óbvias e quase matter of fact, o que dispensaria qualquer análise. O que se perde de vista é o caráter necessariamente cultural dessas necessidades, assim como a estreita relação entre técnica e significado, como mostram diversos exemplos empíricos levantados pela antropologia ao longo das décadas.

A integração de variáveis torna-se mais abrangente quando percebemos fenômenos sociais em termos de práticas e não de objetos. Tal abordagem, aplicada ao estudo da tecnociência, inspira- 
-se na discussão metodológica de Pierre Bourdieu (1997) e na crítica etnometodológica à sociologia da ciência, capitaneada por Michael Lynch (1982, 1993). Os dois autores incorporam a premissa da contingência de arranjos e relações que se formam no interior de práticas diversas. Sem nenhuma pretensão de esgotar a discussão em torno desses autores, apresentamos a seguir algumas consideraçôes ligadas ao estudo de contextos tecnocientíficos.

Bourdieu, ao discutir a importância das práticas na antropologia, recusa posturas objetivistas, que separam o sujeito dos objetos de análise e acreditam em uma objetividade pura; ao mesmo tempo, ele se opõe a posturas subjetivistas, que entendem as impressôes do cientista como único produto possível da ciência social. Fenômenos e relações sociais só existem no momento em que acontecem, pois estão sempre inseridos em fluxos constantes de práticas que se desenrolam ao longo do tempo. Quando se incorpora o fator temporal, percebemos a importância de analisar fenômenos sociais como processos e não como "objetos" - a ação dos sujeitos possui um caráter de indeterminação que precisa ser levado em consideração.

Práticas são, dessa forma, a um só tempo "determinantes e determinadas", em cujo bojo são constituídas as realidades que vivenciamos, inclusive no âmbito da tecnociência. Para Sterne (2003), as realidades não são ontologicamente distintas das práticas sociais: elas ajudam a compor o habitus, ou seja, participam dos processos de incorporação de predisposiçôes dos atores, fazendo parte do social como quaisquer outras práticas. Portanto, ignorar como as tecnologias são vivenciadas "na prática” é deixar de lado todo um espectro de questôes relevantes para entender a maneira pela qual determinadas relações de poder se solidificam, se reproduzem ou são rompidas.

A crítica etnometodológica, ainda que por vias diversas, sugere igualmente um foco analítico no processo e não em objetos ontologicamente separados (Garfinkel, 1967). Michael Lynch, inspirado por essa perspectiva, tem feito ao longo dos últimos anos diversas criticas à sociologia da ciência. No âmago dessas críticas está uma recusa de quaisquer determinismos sociais (além dos tecnológicos), pois, se a tecnociência é "socialmente construída", ou se a tarefa da sociologia da ciência for a de "revelar" a verdade sobre a ciência, mascarada pela ilusão sob a qual viveriam os cientistas (a de que sua atividade é "objetiva”), então estaríamos novamente presos num quadro analítico em cujo centro está a preponderância do social, em detrimento da materialidade dos artefatos, por exemplo.

Para Lynch (1982), um dos erros da sociologia da ciência é exatamente ignorar que cientistas sejam críticos de suas próprias práticas, vivendo sob a ilusão de que seu conhecimento será a revelação do real. Lynch argumenta que cientistas, quando observados em suas práticas de laboratório, se mostram plenamente capazes de perceber e interagir com a contingência dos saberes ali produzidos. Ao ignorar essa capacidade crítica dos cientistas, alguns sociólogos da ciência estariam também se negando a criticar e a refletir sobre suas próprias práticas de conhecimento, tão contingentes e construídas quanto aquelas observadas em laboratórios.

O etnógrafo deve ter sempre em mente a maneira pela qual as técnicas, os saberes e as pessoas interagem para produzir realidades. Como no exemplo dos sistemas de irrigação em Sri Lanka, não se podem analisar somente as relaçôes sociais, nem apenas o que as pessoas dizem sobre as tecnologias, nem exclusivamente os sistemas técnicos. A análise torna-se mais rica ao abordar esses elementos de forma inter-relacionada no espaço e no tempo. Esse quadro teórico contempla, pois, os usos diversos de tecnologias, a mediação das relações sociais por artefatos técnicos e as possibilidades de reorganização de um contexto, catalisadas por novos arranjos tecnológicos.

Práticas tecnocientíficas produzem saberes, poderes, significados e bens materiais. A ideia da "necessidade como motor da invenção" ignora completamente esses aspecto, tornando invisíveis as complexas inter-relações entre sistemas sociais e técnicos que caracterizam qualquer tecnologia na sua expressão viva, da forma como é praticada pelas pessoas. Nenhuma tecnologia é composta somente de máquinas, mas requer sistemas de organização e seres humanos que comandam aspectos específicos de seu funcionamento. Além disso, uma nova tecnologia é sempre projetada dentro de contextos sociais particulares e possui fins específicos, elabo- 
rados de acordo com esses contextos. Os bens ou serviços assim produzidos circulam de formas particulares, completando um ciclo que é "sociotécnico" em toda a sua extensão.

\section{Conclusão}

A ideia de que ciência e tecnologia são práticas contingentes e relacionadas com diversas esferas do mundo social abre caminho para a formulação de questões que atuam na conexão entre ciência e sociedade, no ponto de encontro entre cientistas, máquinas, conhecimentos, artefatos tecnológicos, instituições e símbolos. O laboratório não é mais considerado nos ESCT uma entidade discreta e facilmente delineada: seus contornos estão cada vez menos claros, e os fluxos que o recortam são cada vez mais importantes nos questionamentos atuais sobre ciência e tecnologia. Esses fluxos envolvem conceitos, imagens, relações de poder, artefatos e equipamentos, configurando as práticas laboratoriais como um nódulo de ricos entrecruzamentos que estão no centro de muitas das mais importantes dinâmicas sociais contemporâneas.

Esta perspectiva, aberta para a complexidade dos arranjos sociotécnicos, abre espaço para o estudo de processos, relações e práticas tecnocientíficas, incluindo aspectos sociais, culturais, políticos, institucionais, religiosos e estéticos. Alguns exemplos são as recentes controvérsias a respeito de alimentos transgênicos e sobre o uso de células-tronco em pesquisas no Brasil: atores de diferentes contextos discutem e negociam em arenas políticas, midiáticas e culturais a fim de fazer valer interpretaçôes e práticas distintas envolvendo conhecimentos e artefatos científicos.

Tais estudos seriam, segundo David Hess (2001), etnografias "pós-construcionistas", ou seja, etnografias que exploram as formas pelas quais os conhecimentos podem ser construídos de forma "melhor". Tal compreensão de melhor deveria estar claramente definido, sendo sua contestabilidade abertamente reconhecida de forma epistemológica e política a fim de evitar tanto um discurso propositivo simplista como uma total despolitização das análises.
Ainda um campo de estudos relativamente recente, os ESCT permanecem fonte constante de renovação de diversas áreas disciplinares, colaborando para o entendimento mais perspicaz da sociedade contemporânea. Há muito para ser feito nesse sentido; em países como o Brasil, etnografias da tecnociência podem ajudar na construção de conhecimento e de novas realidades, mais justas e sustentáveis. $\mathrm{Na}$ medida em que pesquisadores ligados aos ESCT estão capacitados para discutir aspectos técnicos e sociais relacionados com problemas tecnocientíficos, eles podem também ajudar a repensar as formas de tecnociência e os arranjos sociotécnicos desejados pelo conjunto da sociedade, atuando de forma reflexiva tanto na pesquisa acadêmica como no desenho e na implementação de novas tecnologias.

A noção de que etnografias da ciência e da tecnologia são formas não só de pensar a realidade, mas também de intervir na construção de novas tecnologias, pode ser muito rica para o campo dos ESCT, que busca consolidar seu crescimento, mas tem que lidar com a desconfiança dos cientistas. Muitos cientistas infelizmente acreditam que a ciência que praticam está completamente livre de quaisquer contingências sociais, e qualquer afirmativa ao contrário tende a ser vista como uma estratégia de deslegitimação de sua posição. A possibilidade de cientistas e etnógrafos da ciência trabalharem juntos com agentes de formulação de políticas públicas sobre ciência e tecnologia permanece uma utopia, mas se trata de um horizonte cada vez mais factível de análise e intervenção na sociedade.

\section{Notas}

1 O movimento teórico conhecido como Teoria Ator-Rede (Actor-Network Theory) não será abordado neste por razões de espaço e coerência do argumento, apesar da proximidade desse campo teórico com diversas correntes da antropologia contemporânea.

2 O termo "tecnociência” é usado aqui para nomear a inter-relação entre ciência e tecnologia no contexto contemporâneo, apesar da usual distinção entre os termos na linguagem corrente. 


\section{BIBLIOGRAFIA}

BLOOR, D. (1976), Knowledge and social imagery. Chicago, The University of Chicago Press.

BOGDAN, R. \& BIKLEN, S. (1994), Investigaçãa qualitativa em educação: uma introdução à teoria e aos métodos. Porto, Editora Porto.

BORDO, S. (1986), "The cartesian masculinization of thought". Signs, 11: 439-456.

(1989) "The body and the reproduction of femininity: a feminist appropriation of Foucault", in S. B. Alison e M. Jaggar (orgs.), Gender/body/knowledge: feminist reconstructions of being and knowing, New Brunswick, Rutgers University Press.

BOURDIEU, P. (1997), Outline of a theory of practice. Cambridge, Cambridge University Press.

BUTLER, J. (1990), Gender trouble: feminism and the subversion of identity. Nova York, Routledge.

CHAZAN, L. K. (2008), “É... tá grávida mesmo! E ele é lindo!' A construção de 'verdades' na ultrassonografia obstétrica”. História, Ciências, Saúde-Manguinhos, 15: 99-116.

CLIFFORD, J. \& MARCUS, G. (1986), Writing culture: the poetics and politics of ethnography. Berkeley, University of California Press.

DOWNEY, G.; DUMIT, J. \& WILLIAMS, S. (1995), "Cyborg anthropology". Cultural Anthropology, 10: 264-269.

FRANKLIN, S. (1995), "Science as culture, cultures of science". Annual Review of Anthropology, 24: 163-184.

FREITAS, R. S. D. (2005), "A sedução da etnografia da ciência". Tempo Social, 17: 229-253.

GARFINKEL, H. (1967), Studies in ethnomethodo$\log y$. Englewood Cliffs, NJ, Prentice Hall.

GOODWIN, C. (1994), "Professional vision". American Anthropologist, 96: 606-633.

HARAWAY, D. (1989), Primate visions: gender, race, and nature in the world of modern science. Nova York, Routledge. (1992), "Ecce homo, ain't (aren't) I a woman, and inappropriated others: the human in a post-humanist landscape", in J. Scott e J. Butler (orgs.), Feminists theorize the political, Nova York, Routledge.
(1995) "Cyborgs and symbionts: living together in the new world order", in C. H. Gray (org.), Cyborg handbook, Nova York, Routledge. . (1997), "The virtual speculum in the new world order". Feminist Review, 55: 22-72. (2000), "Manifesto ciborgue: ciência, tecnologia e feminismo socialista no final do século XX", in T. T. d. Silva (org.), Antropologia do ciborgue: as vertigens do pós-humano, Belo Horizonte, Autêntica.

. (2004), "Situated knowledges: the science question in feminism and the provilege of partial perspective", in S. Harding (org.), The feminist stand point theory reader: intellectual and political controversies, Nova York, Routledge.

HESS, D. (1995), Science and technology in a multicultural world: the cultural politics of facts and artifacts. Nova York, Columbia University Press. (2001), "Ethnography and the development of science and technology studies", in $\mathrm{P}$. Atkinson et al. (orgs.), Handbook of ethnography, Londres, Sage.

KAY, L. (2000), Who wrote the book of life? A history of the genetic code. Stanford, Stanford University Press.

KEATING, E. (2005), "Homo prostheticus: problematizing the notions of activity and computer-mediated interaction". Discourse Studies, 7: 527-545.

KELLER, E. F. (1995), Reconfiguring life: metaphors of Twentieth-Century biology. Nova York, Columbia University Press.

KNORR-CETINA, K. (1981), The manufacture of knowledge: an essay on the constructivist and contextual nature of science. Oxford, Pergamon. . (1983A), "The ethnographic study of scientific work: towards a constructivist interpretation of science", in K. Knorr-Cetina e M. Mulkay (orgs.), Science observed: perspectives on the social study of science, Beverly Hills, Sage. . (1983B), "New developments in science studies: the ethnographic challenge". Canadian Journal of Sociology, 8: 153-177.

. (1992), "The couch, the cathedral and the laboratory: on the relationship between experiment and laboratory in science", in $\mathrm{A}$. Pi- 
ckering (org.), Science as practice and culture, Chicago, University of Chicago Press.

KNORR-CETINA, K. \& AMANN, K. (1990), "Image dissection in natural scientific inquiry". Science, Technology and Human Values, 15: 259-283.

KUHN, T. (1970), The structure of scientific revolutions. Chicago, University of Chicago Press.

LAPLANTINE, F. (1999), Aprender antropologia. São Paulo, Brasiliense.

LATOUR, B. (1990), "Drawing things together", in M. Lynch e S. Woolgar (orgs.), Representation in scientific practice, Cambridge, MIT Press.

(1995), "The 'pedofil' of Boa Vista: a photo-philosophical montage". Common Knowledge, 4: 144-187.

LATOUR, B. (2005), Reassembling the social: an introduction to actor-network theory. Oxford, Oxford University Press.

LATOUR, B. \& WOOLGAR, S. (1997), A vida de laboratório: a produção dos fatos científicos. Rio de Janeiro, Relume-Dumará.

LAW, J. (2009), "Actor network theory and material semiotics", in B. Turner (ed.), The New Blackwell Companion to social theory, Malden, MA, Blackwell, pp. 141-158.

LUNA, N. (2007), Provetas e clones: uma antropologia das novas tecnologias reprodutivas. Rio de Janeiro, Fiocruz.

LYNCH, M. (1981), Art and artifact in laboratory science: a study of shop work and shop talk in a research laboratory. Londres, Keegan Paul.

LYNCH, M. (1982), "Technical work and critical inquiry: investigations in a scientific laboratory". Social Studies of Science, 12: 499-533.

. (1993), Scientific practice and ordinary action: ethnomehodology and social studies of science. Cambridge, Cambridge University Press.

. (2006), "The production of scientific images: vision and re-vision in the history, philosophy and sociology of science", in $\mathrm{L}$. Pauwels (org.), Visual cultures of science: rethinking representational practices in knowledge building and science communication, Hanover, Dartmouth College Press.
LYNCH, M. \& WOOLGAR, S. (1990), Representation in scientific practice. Cambridge, MIT Press.

MARCUS, G. (1995), "Ethnography in/of the world system: the emergence of multi-sited ethnography". Annual Review of Anthropology, 24: 95-117.

MARCUS, G. \& FISCHER, M. J. (1999), Anthropology as cultural critique: an experimental moment in the human sciences. Chicago, The University of Chicago Press.

MARTIN, E. (1998), "Anthropology and the cultural study of science". Science, Technology and Human Values, 23: 24-44.

MAUSS, M. (2005), Sociologia e antropologia. São Paulo, Cosac e Naify.

MERTON, R. K. (1973), The sociology of science. Chicago, The University of Chicago Press.

MONTEIRO, M. (2010a), "Reconfiguring evidence: interacting with digital objects in scientific practice". Computer Supported Cooperative Work, 19: 335-354.

. (2010b), "Beyond the merely visual: interacting with digital objects in interdisciplinary scientific practice". Semiótica, 1-4: 127-147.

MONTEIRO, M. \& KEATING, E. (2009), "Managing misunderstandings: the role of language in interdisciplinary scientific collaboration". Science Communication, 31: 6-28.

NADER, L. (1972), "Up the anthropologist: perspectives gained from studying up", in $\mathrm{D}$. Hymes (org.), Reinventing anthropology, Nova York, Pantheon Books.

OCHS, E.; JACOBY, S. \& GONZALES, P. (1994), "Interpretive journeys: how physicists talk and travel through graphic space". Configurations, 2: 151-171.

PESTRE, D. (1996), "Por uma nova história social e cultural das ciências: novas definiçōes, novos objetos, novas abordagens". Cadernos IG/Unicamp, 6: 3-56.

PFAFFENBERGER, B. (1988), "Fetishised Objects and Humanised Nature: Towards an Anthropology of Technology". Man, 23:236-252.

PFAFFENBERGER, B. (1992) "Social Anthropology of Technology". Annual Review of Anthropology, 21:491-516. 
PICKERING, A. (1993) "The mangle of practice: agency and emergence in the sociology of science. The American Journal of Sociology" 99: 559-589.

RABINOW, P. (1999a), French DNA: trouble in purgatory. Chicago, University of Chicago Press.

RABINOW, P. (1999b), Antropologia da razão: ensaios de Paul Rabinow. Rio de Janeiro, Relume-Dumará.

RABINOW, P. (2000) "Epochs, Presents, Events”, in: M. Lock, et al. (orgs.), Living and working with the new medical technologies: intersections of inquiry. Cambridge, Cambridge University Press.

SÁ, G.J.S. (2005) "Da cultura da diferença à diferença das culturas: A apropriação do conceito de cultura no discurso de primatólogos". Revista de Antropologia, 7: 257-278.

SAUTCHUK, C. E. (2010) "Ciência e técnica", in L. F. D. Duarte (org.), Horizontes das ciências sociais no Brasil: antropologia. São Paulo, ANPOCS.

SISMONDO, S. (2004), An Introduction to science and technology studies. Malden, Blackwell.

STERNE, J. (2003) "Bourdieu, Technique and Technology”. Cultural Studies, 17: 367-389.

VIDICH, A.; LYMAN, S. (2000) "Qualitative methods: their history in sociology and anthropology", in N. Denzin e Y. Lincoln (orgs.), Handbook of qualitative research. Londres, Sage.

WOOLGAR, S. (1982) "Laboratory studies: a comment on the state of the art". Social Studies of Science, 12: 481-498. 


\section{RECONSIDERANDO A ETNOGRAFIA DA CIÊNCIA E DA TECNOLOGIA: TECNOCIÊNCIA NA PRÁTICA}

\author{
Marko Synésio Alves Monteiro \\ Palavras-chave: Ciência e Tecnologia; An- \\ tropologia; Etnografia; Teoria das práticas.
}

Este artigo analisa a metodologia etnográfica na pesquisa de temas ligados à ciência e à tecnologia como forma de discutir os desafios que esse campo apresenta hoje às ciências sociais. A abordagem etnográfica vem sendo cada vez mais utilizada para a análise das relações entre ciência, tecnologia e sociedade. Num movimento paralelo, tais temas têm interessado crescentemente a antropologia. Acreditamos que os estudos antropológicos nessa área oferecem uma perspectiva peculiar, incluindo a análise da ciência e da tecnologia como práticas e a noção de tecnologia como fato social total. Tais abordagens podem enriquecer tanto os estudos sociais da ciência e da tecnologia, como a própria antropologia.

\section{RECONSIDERING THE ETHNOGRAPHY OF SCIENCE AND TECHNOLOGY: TEHNOSCIENCE IN PRACTICE}

\section{Marko Synésio Alves Monteiro}

Keywords: Science and Technology; Anthropology; Ethnography; Theory of practices.

This article discusses ethnography as a methodology for the research of subjects related to science and technology, in order to assess some of the challenges confronted by contemporary social sciences in such domain. The ethnographic approach is becoming a tool increasingly used in the analysis of the relations between science, technology and society. In a parallel movement, such subjects have increasingly become of interest for anthropology. The anthropological studies in this area offer a unique perspective that should be further explored, including the analysis of science as a social practice and the idea of technology as a total social fact. These approaches could enrich both the field of science, technology and society, and the anthropological studies of contemporary science and technology in society.
RECONSIDÉRANT

L'ETHNOGRAPHIE DE LA SCIENCE ET DE LA TECHNOLOGIE: TECHNOSCIENCE DANS LA PRATIQUE

\section{Marko Synésio Alves Monteiro}

Mots-clés: Science et Technologie; Anthropologie; Ethnographie; Théorie des pratiques.

Cet article analyse la méthodologie ethnographique dans la recherche de thèmes liés à la science et à la technologie comme une manière de discuter les défis que ce domaine présente de nos jours aux sciences sociales. L'abordage ethnographique est de plus en plus utilisé pour l'analyse des relations entre la science, la technologie et la société. Dans un mouvement parallèle, de tels thèmes intéressent de façon croissante l'anthropologie. Nous croyons que les études anthropologiques dans ce domaine offrent une perspective particulière, incluant l'analyse de la science et de la technologie en tant que pratiques et la notion de technologie en tant que fait social total. De tels abordages peuvent enrichir aussi bien les études des sciences sociales et de la technologie, comme la propre anthropologie. 